Vol. 1, No. 1, 2020

https://doi.org/

UDK 519.6

\author{
M. Andriychuk ${ }^{1}$ \\ ${ }^{1}$ Pidstryhach Institute for Applied Problems of Mechanics and Mathematics, NASU, \\ ${ }^{1}$ Lviv Polytechnic National University
}

\title{
MODELING THE PLANE RADIATION STRUCTURES CONSISTING OF DISCRETE ELEMENTS
}

(C) Andriychuk M., 2020

Modeling the radiation pattern (RP) of plane arrays has been carried out using the strict electrodynamical solution of the respective direct problem that allows obtaining the representation of RP in the explicit operator form. The system of integral equations of the Hallen type is used for the determination of the current distribution in the apertures of radiators. The optimal excitation coefficients in apertures are determined while minimization of functional presenting the mean-square deviation of the given and synthesized amplitude RPs. The additional terms in the functions are applied for the minimization of radiation in a near zone of array and limitation on the values of excitation coefficients. The computational results demonstrate the quick convergence of the proposed iterative procedure and the ability to synthesize the prescribed amplitude RPs of the various types.

Keywords: plane array, direct electrodynamical problem, synthesis problem, variational approach, nonlinear equation, method of successive approximation, computational modeling

\section{Introduction}

The different antenna systems now are constructed in such a way that they satisfy a series of requirements to their functioning, particularly, they must realize a quick scanning in a wide range of angles and frequencies [1] - [5], as well as to implement other functions at the same time [6] - [10]. Such properties are characteristic for arrays with independent control of elements, firstly with the independent phase distribution in the array's elements [11] - [13]. The majority of methods that have so far been used in the calculation of phased arrays are based on the classical theory of antenna arrays, which does not take into account the mutual influence of neighboring elements [14], as well as on approximate analytical methods and experimental results [15]. It follows from the practice of developing the modern radar antenna arrays, scanning in a wide range of angles, that the mutual coupling of array elements is very significant while determining the array's radiation characteristics. Approximate analytical methods, the effects of mutual coupling are insufficiently taken into account. The development of large phased arrays using experimental methods, when many thousands of antenna elements are used [16] - [17] is too time-consuming and expensive. Therefore, it is necessary to develop effective methods, providing the possibility to determine exactly the electrodynamical characteristics of antenna arrays and to elaborate the effective computation methods that take into account the effects of mutual influence of the array elements.

The proposed approach is based on the consideration of the analysis problem of the array in the strict electrodynamical formulation. The vector character of the electromagnetic (EM) field in the array radiators is taken into account. The vector representation for the characteristics of the plane array's radiation is discussed in the second section. In the following, the procedure to derive the explicit operator representation for the RP is described; an integral equation of Hallen type is derived to determine the excitation currents in the array elements. By this recipe, the mutual coupling of adjacent radiators is taken into account. The variational formulation of the synthesis problem allowing to take into account the different requirements to 
radiation characteristics is applied, and methods of solving the optimization problem are discussed also. The results of numerical modeling that demonstrate the quick convergence of the proposed method of successive approximations, the synthesis results for the different form of the synthesized RPs, as well as the example related to the possibility to take into account the restriction on the field values in a near zone are given.

\section{The electrodynamical statement of analysis problem}

The geometry of plane microstrip array with parallel feeding is shown in Fig. 1. It consists of 20 radiators placed at a distance $d$ from each other. A distance between the array's radiators along the $O x$ and $O y$ axes can be different; and its elements radiate into a homogeneous half-space above the plane of the array.

Since the amplitude RP is considered as input data for the optimization (synthesis) problem, we should have the representation of the array's full RP through the currents in the apertures of separate radiators. Using the assumptions similar to [18], we describe the array's RP using the relations for the EM field of radiators placed in a plane.

In general, the analysis problem consists of determining the EM field's components (including in a far zone of the array) by the values of field (current) in the array's radiators. It is known [19] that the EM field created by a system of plane radiators can be presented in the far zone as

$$
\mathbf{E}(r, \theta, \varphi)=-(k / 4 \pi)\left(e^{-i k r} / r\right) \mathbf{D}(\theta, \varphi),
$$

where

$$
\mathbf{D}(\theta, \varphi)=\left[\mathbf{i}_{r} \times\left(\mathbf{n}-\mathbf{i}_{r}\right) \times \mathbf{N}(\theta, \varphi)\right],
$$

a sign $\times$ denotes vector product of the respective vectors, and

$$
\mathbf{N}(\theta, \varphi)=\iint_{S_{n m}} \sum_{n=-N}^{N} \sum_{m=-M}^{M} \mathbf{U}_{n m}\left(x_{n m}, y_{n m}\right) \times \exp \left[i k\left(x_{n m} \sin \theta \cos \varphi+y_{n m} \sin \theta \sin \varphi\right)\right] d x_{n m} d y_{n m},
$$

where $\mathbf{U}_{n m}$ is the current's distribution in the aperture $S_{n m}$ of $n m$-th radiator, $k$ is the wavenumber.

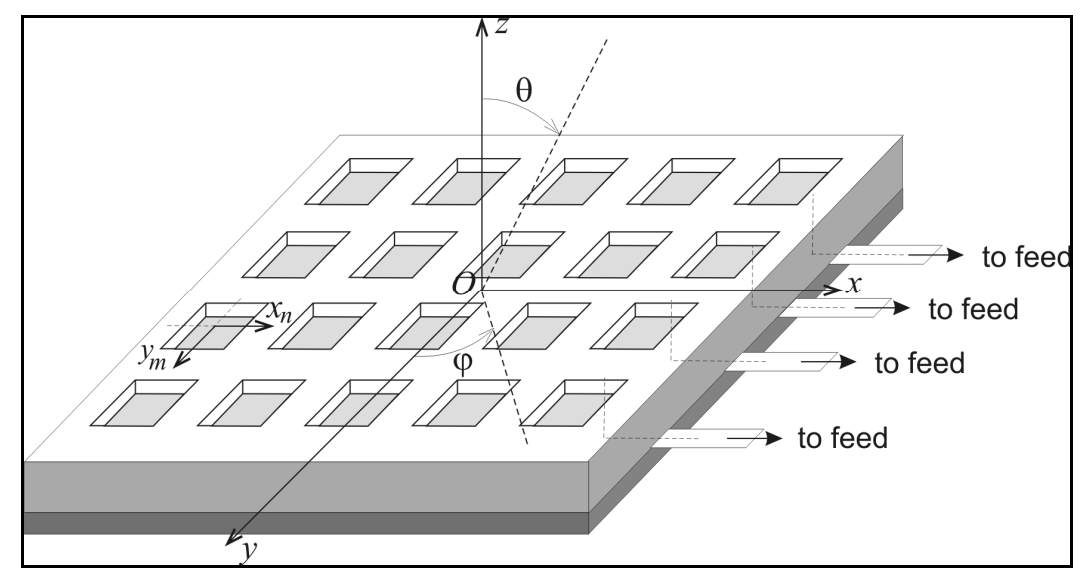

Fig. 1 Geometry of plane microstrip rectangular array with the parallel feeding

A function $\mathbf{D}(\theta, \varphi)$ is RP of the system of plane radiators. Since the angular dependence, the components of the EM field in formula (2) are concentrated in function $\mathbf{N}$, then we will consider right this function as characteristic of radiation.

The vectors $\mathbf{U}_{n m}(x, y)$ of current in the array's elements we present in the form

$$
\mathbf{U}_{n m}(x, y)=U_{x n m}(x, y) \mathbf{i}_{x}+U_{y n m}(x, y) \mathbf{i}_{y} .
$$

It is easy to see that the vector $\mathbf{N}$ can be written similarly:

$$
\mathbf{N}=N_{x} \mathbf{i}_{x}+N_{y} \mathbf{i}_{y},
$$


and if to substitute (4) into (2), we receive

$$
\begin{gathered}
N_{x}=\sum_{n=-N}^{N} \sum_{m=-M}^{M} \iint_{S_{n m}} U_{x n m} \exp \left[i k\left(\sin \theta\left(x_{n m} \cos \varphi+y_{n m} \sin \varphi\right)\right)\right] d x_{n m} d y_{n m}, \\
N_{y}=\sum_{n=-N}^{N} \sum_{m=-M}^{M} \iint_{S_{n m}} U_{y n m} \times \exp \left[i k\left(\cos \theta\left(x_{n m} \cos \varphi+y_{n m} \sin \varphi\right)\right)\right] d x_{n m} d y_{n m} .
\end{gathered}
$$

Substituting (4) into (1), using formulas from [19], and changing the orts $\mathbf{i}_{x}, \mathbf{i}_{y}, \mathbf{i}_{z}$ by $\mathbf{i}_{\theta}, \mathbf{i}_{\varphi}, \mathbf{i}_{r}$, we obtain the formula for vector $\mathbf{D}$ in the spherical coordinate system

$$
\begin{aligned}
& \mathbf{D}(\theta, \varphi)=(1+\cos \theta)\left[\left(N_{x}(\theta, \varphi) \cos \varphi+N_{y}(\theta, \varphi) \sin \varphi\right) \mathbf{i}_{\theta}\right. \\
& \left.-\left(N_{x}(\theta, \varphi) \sin \varphi-N_{y}(\theta, \varphi) \cos \varphi\right) \mathbf{i}_{\varphi}\right] .
\end{aligned}
$$

This relation can be simplified if to introduce a coordinate system in the far zone with orthogonal unit vectors $\mathbf{q}_{1}, \mathbf{q}_{2}, \mathbf{q}_{3}$ [20]. Then

$$
\mathbf{D}(\theta, \varphi)=(1+\cos \theta)\left(N_{x}(\theta, \varphi) \mathbf{q}_{1}+N_{y}(\theta, \varphi) \mathbf{q}_{2}\right) .
$$

So, we receive for vector $\mathbf{D}(\theta, \varphi)$ relation, which is analogous to (5) for vector $\mathbf{N}$, namely both they have the same components $N_{x}(\theta, \varphi)$ and $N_{y}(\theta, \varphi)$, and differ by the unit vectors and multiplier $(1+\cos \theta)$.

The components (6) are independent of one another: each component of the field in the observation point is connected with the respective components of current in the aperture of radiators. This is a significant advantage of the introduction of a coordinate system with unit vectors $\mathbf{q}_{1}, \mathbf{q}_{2}, \mathbf{q}_{3}$ : in the case of the separation of variables in functions that describe the distribution of the EM field in the separate apertures, RP is described by two independent components $N_{x}(\theta, \varphi)$ and $N_{y}(\theta, \varphi)$.

Thus, the system of relations (1) - (8) allows us to consider the solution of the analysis problem in the general three-dimensional case as well as to reduce it to simpler cases of determining the characteristics of radiation in two mutually perpendicular planes.

\section{Calculation of the RP of array}

The calculations of the array's RP is performed based on the model, taking into account the separation of the variables in the excitation currents $\mathbf{U}_{n m}(x, y)$ of separate radiators into two independent components $U_{x n m}$ and $U_{y n m}$. The 3D RP has the following form

$$
f\left(t_{1}, t_{2}\right)=A a \equiv \sum_{n=-N}^{N} a_{n} e^{i c_{1} n t_{1}} f_{n m}\left(t_{2}\right),
$$

where the generalized coordinates $t_{1}$ and $t_{2}$ determines as $t_{1}=\cos \theta \cos \varphi / \sin \alpha_{1}, t_{2}=\sin \theta \cos \varphi / \sin \alpha_{2}$, $c_{1}=k d_{1} \sin \alpha_{1}, c_{2}=k d_{2} \sin \alpha_{2}, d_{1}$ and $d_{2}$ are distances between adjacent radiators along the $O x$ and $O y$ axes respectively, $\alpha_{1}$ and $\alpha_{2}$ are the angles outside of which the prescribed RP $F\left(t_{1}, t_{2}\right)$ is equal to zero. The set of complex coefficients $\left\{a_{1}, \ldots a_{N}\right\}$ corresponds to the excitation of the separate linear subarrays.

Function $f_{n m}\left(t_{2}\right)$ in (9) describes the RP of $n$-th linear subarray in the presence of the rest $2 N$ subarrays. This function is presented in the form

$$
f_{n m}\left(t_{2}\right)=\sum_{m=-M}^{M} I_{n m} e^{i c_{2} m t_{2}}, n=-N,-N+1, \ldots, N-1, N,
$$

where

$$
I_{n m}(x, y)=\sum_{m=1}^{N} b_{m} U_{n m}(x, y), n=-N,-N+1, \ldots, N-1, N .
$$


Functions $U_{n m}(x, y)$ are currents in the aperture of $n m$-th radiator in the condition that the radiators of adjacent subarrays do not affect their value. If to take into account the mutual coupling of all radiators, and the amplitude of a normal wave, which is propagated in the radiators of $m$-th subarray is $b_{m}$, then the full current in the aperture of $\mathrm{nm}$ - th radiator is determined by the formula (11).

For practical applications, it is sufficient to consider the case when only one wave propagates in the aperture of $\mathrm{nm}$ - th radiator, and then the total currents are completely determined by the formula (11). In this case, the solution to the direct problem is obtained from the following system of integral equations [21]

$$
\begin{aligned}
& {\left[\left[n_{n m}^{r}\left(\operatorname{grad} \operatorname{div}+k^{2}\right) \times \sum_{n=-N}^{N} \sum_{m=-M}^{M} \int_{S_{n n}} \mathbf{U}_{n m}\left(Q_{n m}\right) G\left(P, Q_{n m}\right) d S_{n m}\right] \times \stackrel{r}{n_{n m}}\right]} \\
& =-i \omega \varepsilon\left[\left[r_{n m}^{r} \times E_{\tau n m}^{r}(P)\right] \times r_{n m}^{r}\right],
\end{aligned}
$$

where ' $_{n m}$ is outside normal to $n m$-th radiator, $G\left(P, Q_{n m}\right)$ is Green's function of the half-space, $E_{\tau n m}(P)$ is the tangential component of the electric field in the aperture of $n m-$ th radiator.

Solving (12), we can get the explicit relation for RP using the current distributions $\left\{U_{n m x}, U_{n m y}\right\}$ in radiators. The numerical procedure for solving (12) is based on the one used for solving a similar integral equation in the case of a $2 \mathrm{D}$ waveguide array [22].

Therefore, using formulas (10), (11) and solutions $U_{n m}(x, y)$ to system (12), we can write the RP (9) as

$$
f\left(t_{1}, t_{2}\right)=A c \equiv \sum_{n=-N}^{N} \sum_{m=-M}^{M} c_{n m} e^{i\left(c_{1} n t_{1}+c_{2} m t_{2}\right)} \bar{U}_{n m}(x, y),
$$

where $\bar{U}_{n m}(x, y)$ is the average current value in the aperture of $n m$ - th radiator, and unknown coefficients $c_{n m}$ are determined as $c_{n m}=a_{n} b_{m}$ ?

\section{Calculation of the field values in a near zone}

To obtain the explicit relation between current distributions $I_{n m}$ in the array elements and the value of field components in a near zone, we will use the formula for electric vector potential [18]

$$
\mathbf{A}_{F r}^{e}(r, \theta, \varphi)=\frac{e^{-i k r}}{4 \pi R} \int_{V} \mathbf{I}\left(x^{\prime}, y^{\prime}, z^{\prime}\right) e^{i k\left[r^{\prime} \cos \alpha+\frac{r^{\prime 2}}{2 r}\left(1-\cos ^{2} \alpha\right)\right]} d V
$$

where

$$
R \approx r\left[1-\frac{r^{\prime}}{r} \cos \alpha+\frac{r^{\prime 2}}{2 r^{2}}\left(1-\cos ^{2} \alpha\right)\right] \square
$$

that is we will confine by the value of the order $O\left(1 / r^{2}\right)$. In the case of the plane array

$$
r^{\prime} \cos \alpha=x^{\prime} \sin \theta \cos \varphi+y^{\prime} \sin \theta \sin \varphi
$$

because the array is placed in the $x^{\prime} O y^{\prime}$ plane, and coordinates $x^{\prime}$ and $y^{\prime}$ correspond to $x^{\prime}-$ and $y^{\prime}$ coordinates of array radiators.

Similarly to formula (9), $A_{F r}^{e}(r, \theta, \varphi)$ can be presented in the form

$$
\begin{aligned}
& \mathbf{A}_{F r}^{e}(r, \theta, \varphi)=\frac{e^{-i k r}}{4 \pi R} \sum_{m=-M_{1}}^{M_{1}} \sum_{n=-N_{1}}^{N_{1}} f_{n m}\left(t_{1}, t_{2}\right) \stackrel{r}{I_{n m}} \times \\
& \exp \left[i\left(n k d_{1} \sin \theta \cos \varphi+m k d_{2} \sin \theta \sin \varphi\right)\right] v_{n m}\left(r, r^{\prime}, \theta, \varphi\right),
\end{aligned}
$$

where

$$
v_{n m}\left(r, r^{\prime}, \theta, \varphi\right)=\exp \left[i\left(x_{n m}^{2}+y_{n m}^{2}-\left(x_{n m} \sin \theta \cos \varphi+y_{n m} \sin \theta \sin \varphi\right)^{2}\right) / 2 r\right],
$$

values ${ }^{\prime}{ }_{n m}$ take into account the vector character of current distributions in the array elements, and value $r^{\prime}$ is replaced by $\sqrt{x_{n m}^{2}+y_{n m}^{2}}$ for each array element. In practice, assuming the separation of $I_{n m}$ values 
into two directions $O x^{\prime}$ and $O y^{\prime}$, we can consider the values of $A_{F r}^{e}(r, \theta, \varphi)$ independently in the above two directions.

Assuming the respective distribution of EM field components in Fresnel zone, we receive the formulas for $\mathbf{H}$ and $\mathbf{E}$ components

$$
\begin{array}{r}
H_{r}=0, H_{\theta}=i k A_{\varphi}^{e}, H_{\varphi}=-i k A_{\theta}^{e}, \\
E_{r}=0, E_{\theta}=-i \omega \mu A_{\theta}^{e}, E_{\varphi}=-i \omega \mu A_{\varphi}^{e} .
\end{array}
$$

To obtain formulas (20), the known relation

$$
\mathbf{E}=-\frac{i}{\omega \varepsilon} \operatorname{rot} \mathbf{H}
$$

between $\mathbf{E}$ and $\mathbf{H}$ components in the free space is used.

Consequently, we have the formulas (17), (19), or (17), (20) for calculations of respective EM field components. They can be interpreted as some linear operator $B$ (because the dependence of field components on the current distributions $\dot{I}_{n m}$ in the array elements is linear one) for calculation $E$ and $H$ components by current distributions ${ }^{\prime} I_{n m}$.

\section{Statement of the synthesis problem for the array}

When considering the analysis problem for a plane rectangular array, it was found that, depending on the properties of the EM field in the apertures of radiators and a far zone, the RP can be considered in the general three-dimensional case, as well as in the case of its separation into two independent functions. Since in the process of solving the synthesis problem (inverse problem) it is necessary to solve the analysis problem repeatedly, this approach, on the one hand, makes it possible to significantly reduce the calculations, and on the other, to consider more accurate models of the analysis problems, the result of a solution to which is explicit analytical expressions for RPs. For example, consideration of the analysis problem in the plane $x O y$ can be carried out taking into account the mutual coupling of the array's separate radiators [23]. In this case, to find the array's RP, it is necessary to have the value of the currents in the radiators distributed along the axes $O x$ and $O y$. This problem is reduced to a system of integral equations [23], which is solved effectively by the collocation method or the Ritz method [24].

Since in the process of designing the antennas it is necessary to satisfy the different demands of the radiation characteristics, it is useful to formulate the synthesis problem as a variational one. The optimization criterion (functional) is formulated in such a way that a series of demands to the radiation characteristics are satisfied [25]. The value of the mean-square deviation of the given (prescribed) $F$ and synthesized (created by an antenna) $|f|$ amplitude RPs is chosen as the optimization criterion. This function can be supplemented by terms that allow forming the EM field with specified properties in the near or middle (Fresnel) zone of the array. The proposed functional has the form

$$
\sigma=\int_{-1}^{1}\left[q\left(t_{1}, t_{2}\right)\left(F\left(t_{1}, t_{2}\right)-\left|f\left(t_{1}, t_{2}\right)\right|\right)\right]^{2} d t_{1} t_{2}+\sum_{i=1}^{K} q_{i}\left(S_{i}\right)\left|u_{i}\left(S_{i}\right)\right|^{2} d S_{i}+\alpha\|\mathbf{c}\|^{2} .
$$

The first term minimizes the mean square deviation of the given and synthesized amplitude RPs; the second term minimizes the values $u_{i}\left(S_{i}\right)$ of the fields in the given domains of the near array's areas $S_{i}$. The third term with the square of amplitudes of the excitation coefficient $c_{n m}$ minimizes the vector norm: for physical reasons, it allows to exclude from the solution the currents that have high reactivity [26]. A function $q\left(t_{1}, t_{2}\right)$ is used to improve the approximation to created amplitude $\mathrm{RP}\left|f\left(t_{1}, t_{2}\right)\right|$ in certain angular coordinate ranges. For this goal, its value is increased within this range compared to the values outside. A series of peculiar requirements can be imposed on the synthesized amplitude PR depending on the engineering specifications of the constructed array, see for example [27]. 


\section{Solving the optimization problem}

The optimal coefficients $c_{n m}$ are determined by minimizing the functional $\sigma$. Equating the gradient $\sigma$ concerning values $U_{n m}$ to zero, we obtain a corresponding system of nonlinear Euler equations [25]

$$
\alpha c_{n m}+A_{n m}^{*}\left[q\left(t_{1}, t_{2}\right)\left(f\left(t_{1}, t_{2}\right)-F\left(t_{1}, t_{2}\right) \times \exp \left(i \arg f\left(t_{1}, t_{2}\right)\right)\right]+\sum_{i=1}^{K} B_{n m}^{*}\left[q_{i} u_{i}(x, y)\right]=0 .\right.
$$

Here $A$ is a linear operator determined by (13); $A_{n m}^{*}$ is operator adjoint to $A$ [25] (its $n m$ - th component); $B$ is the operator of calculating the values of the fields $u_{i}$ in the near zone by coefficients $c_{n m}$, and $B_{m m}^{*}$ is the operator adjoint to $B$ [25]. The index $n m$ of the operator $A^{*}$ and $B^{*}$ indicates that the result of their action is related to the corresponding element of the array.

The method of successive approximation

$$
\alpha c_{n m}^{(p+1)}+A_{n m}^{*}\left(p f^{(p+1)}\right)+\sum_{i=1}^{K} B_{n m}^{*}\left(p_{i} u_{i}^{(p+1)}\right)=A_{n m}^{*}\left(p F \exp \left(i \arg f^{(p)}\right)\right), p=1,2, \ldots
$$

is used to solve the system (23). Here $p$ is the iteration number. A characteristic feature of this iterative process is that it reduces the value of the function $\sigma$ at each iteration [23]. Since the value $\sigma$ is bounded by zero below, it follows that this iterative process is convergent in understanding the minimum of functional value.

Another approach to solving an optimization problem is to apply gradient methods for direct minimization $\sigma$. The most effective of the methods used is the generalized gradient method, proposed firstly in [28]. Its advantage is that it uses information from all previous iterations at the $p+1$-th step of the iterative process. Each of these methods has its advantages depending on the structure of the array.

\section{Numerical modeling}

The convergence of the iterative procedure

The computational results aimed to establish the characteristics of convergence of iterative procedure (24) are presented in Fig. 2 and Fig. 3. The influence of the weighting parameter $\alpha$ on the speed of convergence is presented here. The quantity of the array's radiators is equal to $11 \times 11$, the prescribed amplitude RP is $F\left(t_{1}, t_{2}\right)=\left|\sin \left(\pi t_{1}\right) \| \sin \left(\pi t_{2}\right)\right|$. In Fig. 2, the results are shown for the value of additional optimizing parameters $\theta=0.1$ [29], which is applied to improve the convergence of the iterative process (24). One can see that the convergence is satisfactory for all the considered values of the parameter $\alpha$. The visible difference in the values of $\left|f_{n+1}-f_{n}\right|$ at the first iterations is observed and this value grows if the value $\alpha$ increases. It is equal to $0.02133,0.03142,0.07110,0.1250$, and 0.1671 for $\alpha=1.5, \alpha=1.0$, $\alpha=0.5, \alpha=0.3$, and $\alpha=0.2$ respectively. Starting at the $20^{\text {th }}$ iteration, the values $\left|f_{n+1}-f_{n}\right|$ become close for all the considered $\alpha$, and they differ in the not more than $10^{-4}$ in the $40^{\text {th }}$ iteration. The convergence becomes worse if $\alpha$ decreases and the iterative process does not converge if $\alpha$ verge towards 0.1 . The results presented in Fig. 3 demonstrate that the quality of convergence depends on the parameter $\theta$ considerably. So, the values $\left|f_{n+1}-f_{n}\right|$ are $0.04594,0.06702,0.1146,0.1588$, and 0.2030 for $\alpha=1.5$, $\alpha=1.0, \alpha=0.5, \alpha=0.45$, and $\alpha=0.43$ respectively. These values are the same order in the $40^{\text {th }}$ iteration as in the previous example, but the iterative procedure becomes non-convergent starting on $\alpha=0.42$. This concerns the character of an iterative process; however, the quality of approximation to the prescribed amplitude RP $F$ is determined by the values of functional (22). Since this is an integral characteristic, the values $\sigma$ are of order larger than the deviation of functions $\left|f_{n+1}\right|$ and $\left|f_{n}\right|[30]$.

The synthesis of specific RPs

The synthesis results are presented for the array and the prescribed amplitude RP the same as in the previous examples in Fig. 4. The distance $d$ between separate radiators was chosen less than $\lambda / 2$ that gives the possibility to obtain the main lobe of RP without deep gaps (zeros) [31]. The restrictions on the near field's values were not specified; i.e., the second term in (22) is equal to zero. This allows us to obtain the synthesized 
amplitude RP $\left|f\left(t_{1}, t_{2}\right)\right|$ with a very small level of sidelobes less than $-100 \mathrm{~dB}$; and the difference between values of $F\left(t_{1}, t_{2}\right)$ and $\left|f\left(t_{1}, t_{2}\right)\right|$ does not exceed $2 \mathrm{~dB}$ in the main lobe. The amplitudes of optimizing coefficients $c_{n m}$ are shown in Fig. 5. One can see that the qualitative characteristic of $c_{n m}$ value is similar to the property of given and synthesized RPs, namely the value of the central coefficient $c_{n m}$ is equal to zero.

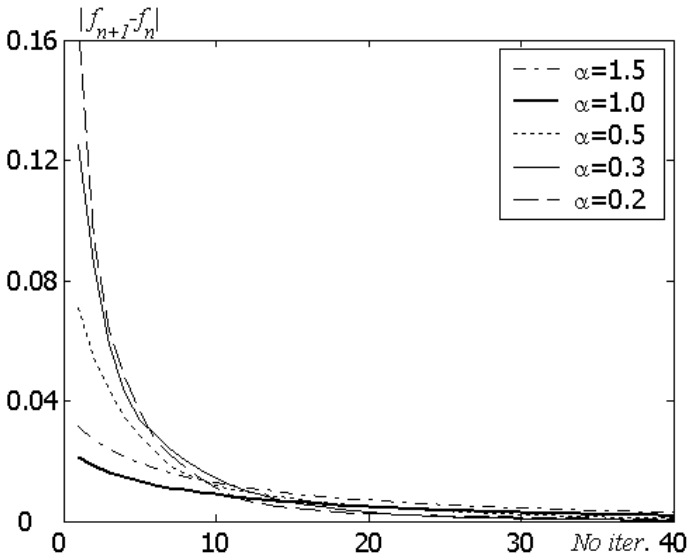

Fig. 2. The error of the iterative process (24) in determining the synthesized $R P\left|f_{n}\right|$ versus the number $n$ of iteration, $\theta=0.1$.

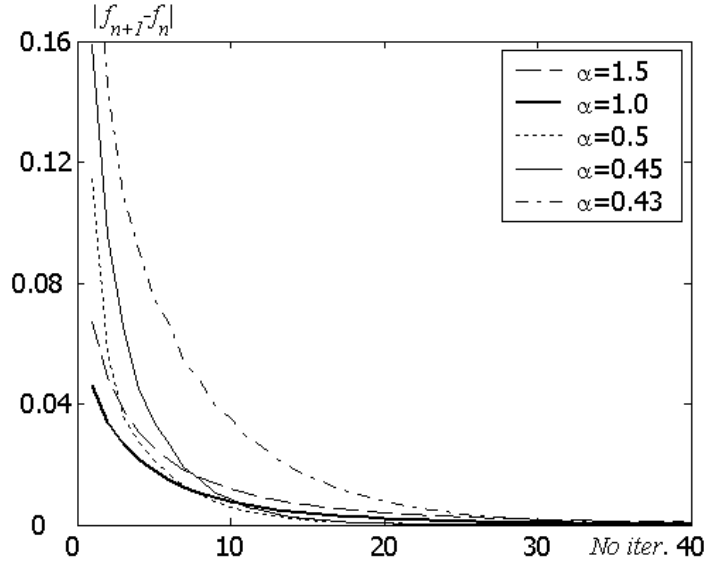

Fig. 3. The error of the iterative process (24) in determining the synthesized $R P\left|f_{n}\right|$ versus the number $n$ of iteration, $\theta=0.3$.

The properties $c_{n m}$ are similar also to distributions of amplitudes $\left|U_{n m}\right|$ of currents in the array elements, which are obtained as a result of solving equation (12).

The numerical calculations done for the different prescribed amplitude RPs show that the quality of approximation (value of functional (22)) essentially depends on the number of radiators, as well as of the value of the parameter $k$, which defines the frequency of radiation.

The Restriction on the Field in a Near Zone

The values of radiation power density (RPD) were minimized in the prescribed points of a near zone; the results are given in Fig. 6 and Fig. 7. The RPD is calculated as

$$
\mathrm{RPD}=1 / 2 \operatorname{Re}\left[\mathbf{E} \times \mathbf{H}^{*}\right]\left(\mathrm{W} / \mathrm{m}^{2}\right),
$$

where the components $\mathbf{E}$ and $\mathbf{H}$ are calculated by formulas (19), (20).

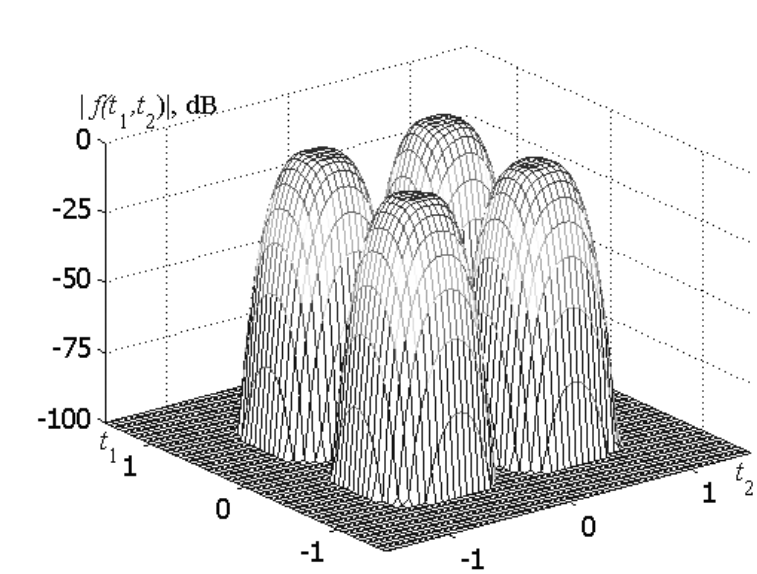

Fig. 4. The amplitude of synthesized RP for the four-lobes prescribed amplitude $R P F$

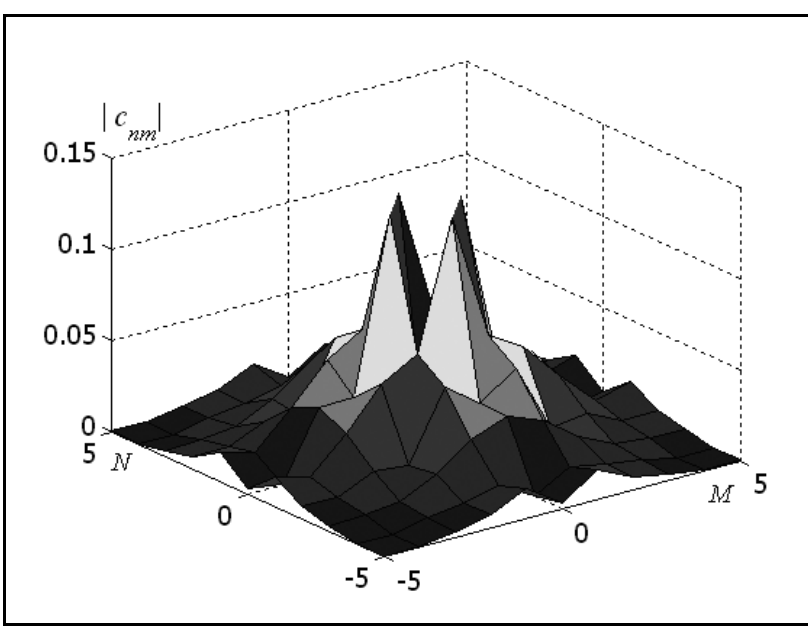

Fig. 5. The amplitude distribution of optimal excitation coefficients $c_{n m}$ in the array's elements 
The requirement to form zero was stated for the distance $r=0.5 \mathrm{~m}$ of array at the next points: $\theta= \pm \pi / 4, \varphi=\pi$. This allowed us to achieve the decrement of the RPD values from $0.1902 \mathrm{~W} / \mathrm{m}^{2}$ to $0.0327 \mathrm{~W} / \mathrm{m}^{2}$ that is $19.1 \%$ of its initial value. The values of the RPD for the rest of $\theta$ and $\varphi$ angles increased not more than $10.2 \%$.

The numerical calculations carried out for the different prescribed amplitude RPs show that the quality of approximation (value of functional (22)) essentially depends on the number of radiators, as well as of the value of the parameter $k$, which defines the frequency of radiation.

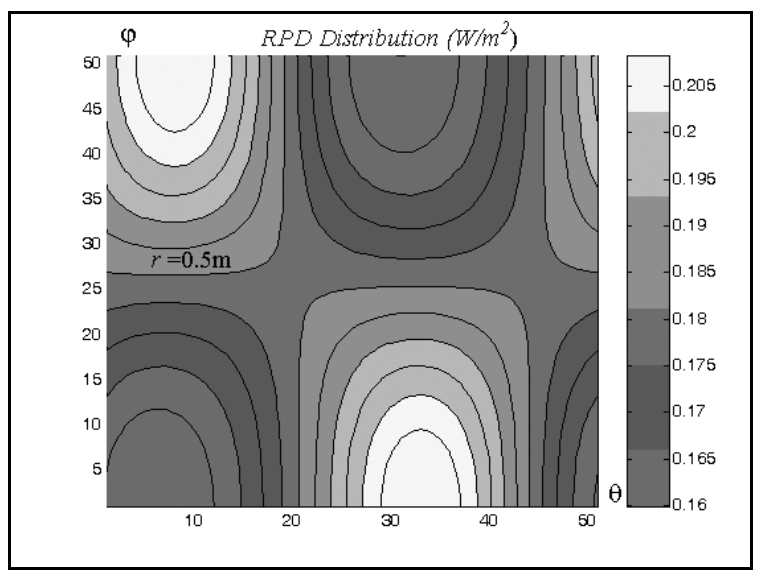

Fig. 6. The initial distribution of the RPD at $r=0.5 \mathrm{~m}$

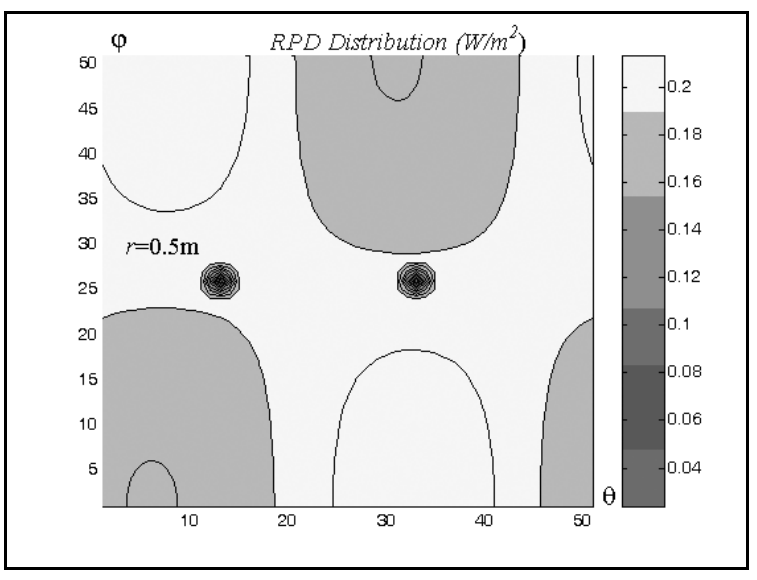

Fig. 7. The RPD with forming zero in two points $r=0.5 \mathrm{~m}$

\section{Conclusion}

The variational approach was proposed for solving the synthesis problem of plane arrays according to the prescribed amplitude RP. The advantage of the approach is that the mutual coupling of the array's radiators is taken into account that allows us to consider the synthesis problem as a determination of the excitation coefficients of separate radiators.

Determination of the above coefficients is implemented in the process of solving the system of nonlinear Euler equations. An effective iteration procedure was proposed for solving this system of equations. The number of iterations to obtain the exactness in the range of $0.1 \%-0.05 \%$ does not exceed 50 for the considered set of prescribed RP $F\left(t_{1}, t_{2}\right)$.

The developed software allows us to simulate the directivity characteristics of plane arrays in a wide range of their geometrical and electrophysical parameters.

1. Mailloux R. J. Phased Array Antenna Handbook, Second Edition, Artech House Antennas and Propagation Library, 2005.

2. Rupakula B., Aljuhani A. H. and Rebeiz G. M., "Limited scan-angle phased arrays using randomly grouped subarrays and reduced number of phase shifters”, IEEE Transactions on Antennas and Propagation, vol. 68, no. 1, pp. 70-80, Jan. 2020, DOI: 10.1109/TAP.2019.2935100.

3. Mailloux R. J. Electronically Scanned Arrays, London: Morgan \& Claypool, 2007.

4. Zou W., Qu S., and Yang S., "Wideband wide-scanning phased array in a triangular lattice with electromagnetic bandgap structures”, IEEE Antennas and Wireless Propagation Letters, vol. 18, no. 3, pp. 422-426, March 2019, DOI: 10.1109/LAWP.2019.2893174.

5. Skobelev S. Phased Array Antennas with Optimized Element Patterns, Artech House Antennas and Propagation Library, 2011.

6. Liang Z., Lv S., Li Y., Liu J., and Long Y., "Compact folded slot antenna and its entire arrays with high gain and vertical polarization”, IEEE Antennas and Wireless Propagation Letters, vol. 19, no. 5, pp. 786-790, May 2020, DOI: 10.1109/LAWP.2020.2980249. 
7. Yang J. and Kishk A., "A novel low-profile compact directional ultra-wideband antenna: The self-grounded bow-tie antenna”, IEEE Transactions on Antennas and Propagation, vol. 60, no. 3, pp. 1214-1220, March 2012, DOI: 10.1109/TAP.2011.2180317.

8. Bahadori K. and Rahmat-Samii Y., "An array-compensated spherical reflector antenna for a very large number of scanned beams”, IEEE Transactions on Antennas and Propagation, vol. 53, no. 11, pp. 3547-3555, Nov. 2005, DOI: 10.1109/TAP.2005.858844.

9. Kim S. and Nam S., "A compact and wideband linear array antenna with low mutual coupling”, IEEE Transactions on Antennas and Propagation, vol. 67, no. 8, pp. 5695-5699, Aug. 2019, DOI: 10.1109/TAP.2019.2922833.

10. Lema G. G., Tesfamariam G. T., and Mohammed M. I., "A novel elliptical-cylindrical antenna array for radar applications”, IEEE Transactions on Antennas and Propagation, vol. 64, no. 5, pp. 1681-1688, May 2016, DOI: 10.1109/TAP.2016.2539370.

11. Visser H. J. Array and Phased Array Antenna Basics, Chichester, UK: John Wiley \& Sons, 2006.

12. Naqvi A. H., Lim S., "Review of recent phased arrays for millimeter-wave wireless communication", Sensors, vol. 18, 3194, 2018.

13. Zang J. W., Alvarez-Melcon A., Gomez-Diaz J. S. Nonreciprocal Phased-Array Antennas, Phys. Rev. Applied, vol. 12, 054008, 2019.

14. Collin R. E., Zucker F. J. Antenna Theory. Part 1, New York: McGraw-Hill, 1969.

15. Pandey A. Practical Microstrip and Printed Antenna Design, Boston, US: Artech House, 2019.

16. Four kids N. Advanced Array Systems. Applications and RF Technologies, San Francisco, CA, USA: Academic, 2000.

17. Matekovits L., Laza V. A., and Vecchi G., "Analysis of large complex structures with the synthetic-functions approach”, IEEE Trans. Antennas Propag., vol. 55, no. 9, pp. 2509-2521, Sept. 2007.

18. Davidson D. B. Computational Electromagnetics for RF and Microwave Engineering. Cambridge: Cambridge University Press, 2011.

19. Feld Ya. N. Antennas of a Centimeter Range, Moscow: Sov. Radio, 1950. (In Russian).

20. Zelkin E. G., Sokolov V. G. Methods of Antenna Synthesis. Phased Antenna Arrays and Antennas with Plane Aperture, Moscow: Sov. Radio, 1980. (In Russian).

21. Chaplin A. F. Analysis and Synthesis of Antenna Arrays, Lviv: Vyshcha Shkola, 1987. (In Ukrainian).

22. Li R., McNamara D. A. and G. Wei., "Evaluation of the available directivity of a radiating structure in terms of its characteristic mode content”, IEEE Transactions on Antennas and Propagation, vol. 67, no. 10, pp. 66866691, Oct. 2019, DOI: 10.1109/TAP.2019.2925184.

23. Andriychuk M. I., Savenko P. O., "Synthesis of a waveguide array with due regard for the mutual coupling of radiators", in Proc. of International Conference on Mathematical Methods in Electromagnetic Theory (MMET2000), Kharkiv, Ukraine, Sept. 12-15, vol. 2, pp. 604-606.

24. Peterson A. F., Ray S. L., Mittra R. Computational Methods for Electromagnetics, New York: Wiley, IEEE Press, 1998.

25. Andriychuk M. I. Antenna Synthesis through the Characteristics of Desired Amplitude, Newcastle, UK: Cambridge Scholars Publishing, 2019.

26. Bulatsyk O. O., Katsenelenbaum B. Z., Topolyuk Yu. P., Voitovich N. N. Phase Optimization Problems: Applications in Wave Field Theory. Weinheim, WILEY-VCH, 2010.

27. Andriychuk M. I., Voitovich N. N., "Antenna synthesis according to power radiation pattern with the condition of norm equality”, in Proc. of 2013 XVIIIth International Seminar/Workshop on Direct and Inverse Problems of Electromagnetic and Acoustic Wave Theory (DIPED), Sept. 23-26, 2013, Lviv, Ukraine, pp. 137-140.

28. Andriychuk M. I., Voytovich N. N., "Synthesis of a closed planar antenna with a given amplitude pattern", Soviet Journal of Communications Technology \& Electronics (English translation of Radiotekhnika I Elektronika), vol. 30. no. 5, pp. 35-40, 1985.

29. Savenko P., "Computational methods in the theory of synthesis of radio and acoustic radiating systems", Applied Mathematics, vol. 4, no 3, pp. 523-549, 2013, DOI: 10.4236/am.2013.43078.

30. Andriychuk M., Kuleshnyk Ya., "Synthesis of plane waveguide array based on a strict solution of analysis problem", in Proc. of 2020 IEEE XXVth International Seminar/Workshop Direct and Inverse Problems of Electromagnetic and Acoustic Wave Theory (DIPED), September 15-18, 2020, Tbilisi, Georgia, pp. 115-120.

31. Balanis C. A. Antenna Theory: Analysis and Design, $4^{\text {th }}$ ed., Hoboken, NJ, USA: John Wiley and Sons, 2016. 
М. Андрійчук Інститут прикладних проблем механіки і математики ім. Підстригача, НАНУ

Національний університет "Львівська політехніка"

\section{МОДЕЛЮВАННЯ ПЛОСКИХ ВИПРОМІНЮЮЧИХ СТРКУТУР, ЯКІ СКЛАДАЮТЬСЯ 3 ДИСКРЕТНИХ ЕЛЕМЕНТІВ}

\section{(C) Андрійчук М., 2020}

Моделювання діаграм випромінювання (ДВ) плоских антенних граток проводиться на основі строгого електродинамічного розв'язку відповідної прямої задачі, що дозволяс отримати представлення ДВ у явній операторній формі. Система інтегральних рівнянь типу Галлена використовується для визначення розподілу струму в апертурах випромінювачів. Оптимальні коефіціснти збудження в елементах гратки визначаються шляхом мінімізації функціоналу, що представляс середньоквадратичне відхилення заданої та синтезованої амплітудних ДВ. Додаткові умови у функціоналі застосовуються для мінімізації випромінювання в ближній зоні гратки та обмеження амплітуд коефіціснтів збудження. Результати обчислень демонструють швидку збіжність запропонованого ітераційного методу та можливість синтезувати задані амплітудні ДВ різних типів.

Ключові слова: плоска гратка, пряма електродинамічна задача, задача синтезу, варіаційний підхід, нелінійне рівняння, метод послідовних наближень, числове моделювання 